\title{
Predicting deep-brain stimulation frequencies to suppress pathological population oscillations in a network model of Parkinson's disease
}

\author{
Abbey B Holt ${ }^{1 *}$, Theoden I Netoff ${ }^{2}$ \\ From Twenty Second Annual Computational Neuroscience Meeting: CNS*2013 \\ Paris, France. 13-18 July 2013
}

Deep-brain stimulation (DBS) is used to treat medicationrefractory Parkinson's disease (PD). However, tuning stimulation parameters requires time intensive visits with a clinician using a trial-and-error process until therapy is achieved with minimal side effects [1]. There is a need for a systematic approach to determining DBS parameters from the patient's physiological response to the stimulus. It is hypothesized that oscillations in the basal ganglia are responsible for many motor signs of PD [2] and that DBS works by disrupting these pathological oscillations. These oscillations arise from the excitatory-inhibitory loop between subthalamic nucleus (STN) and globus pallidus external (GPe) [3]. Periodic forcing of an oscillating system can induce chaos at certain frequencies [4]. When the system is chaotic it behaves aperiodically thereby suppressing the pathological oscillations. From a system's phase response curve (PRC), it is possible to determine at which stimulus frequencies and amplitudes chaotic responses will occur. Here we measure PRCs and predict optimal stimulation frequencies in a physiologically realistic computational model of STN DBS [5]. The model consists of 300 neurons in GPe and 100 neurons in STN and was tuned to reproduce non-human primate data. In the PD state, GPe activity produces a strong $32 \mathrm{~Hz}$ oscillation similar to the beta oscillations observed in the animal model. DBS pulses are applied to the STN and its efferent connections. Stimulation at $136 \mathrm{~Hz}$, commonly used clinically, suppresses the beta oscillation. From low frequency stimulation $(2 \mathrm{~Hz})$ we are able to estimate the PRC of the population oscillation to the DBS pulse. From the measured PRC the stimulus frequencies that induce chaos in

\footnotetext{
* Correspondence: holt0437@umn.edu

'Department of Neuroscience, University of Minnesota, Minneapolis, Minnesota, 55455, USA

Full list of author information is available at the end of the article
}

the STN-GPe loop are predicted. The STN was then stimulated over a range of frequencies and the power of the $32 \mathrm{~Hz}$ population oscillation measured. There is a strong correlation between the stimulus frequencies predicted to produce chaos from the PRC and the simulations where beta is suppressed. This indicates that it may be possible to predict DBS frequencies to successfully eliminate pathological oscillations based on a PRC measured from a patient using low frequency stimulation. Novel contributions of this work are methods of measuring PRCs from population activity and utilizing them to accurately predict stimulus frequencies that suppress oscillations in a model of the basal ganglia. We propose that this approach can be applied to patients in which electrophysiology measurements can be made simultaneously with stimulation. This approach to tuning stimulation parameters may dramatically reduce tuning time and improve efficacy for treatment of PD.

\section{Acknowledgements \\ The authors would like to acknowledge funding from Medtronic and the University of Minnesota GPN Training Grant: T32 GM008471 20}

\section{Author details}

'Department of Neuroscience, University of Minnesota, Minneapolis, Minnesota, 55455, USA. ${ }^{2}$ Department of Biomedical Engineering, University of Minnesota, Minneapolis, Minnesota, 55455, USA.

Published: 8 July 2013

\section{References}

1. Volkmann J, Herzog J, Kopper F, Deuschl G: Introduction to the programming of deep brain stimulators. Mov Disord 2002, 17(Suppl 3): S181-7.

2. Dostrovsky J, Bergman H: Oscillatory activity in the basal gangliarelationship to normal physiology and pathophysiology. Brain 2004, 127(Pt 4):721-722. 
3. Tachibana Y, Iwamuro H, Kita H, Takada M, Nambu A: Subthalamo-pallidal interactions underlying parkinsonian neuronal oscillations in the primate basal ganglia. Eur J Neurosci 2011, 34(9):1470-1484.

4. Wilson CJ, Beverlin B, Netoff T: Chaotic desynchronization as the therapeutic mechanism of deep brain stimulation. Front Syst Neurosci 2011, 5:50.

5. Hahn PJ, Mclntyre CC: Modeling shifts in the rate and pattern of subthalamopallidal network activity during deep brain stimulation. $J$ Comput Neurosci 2010, 28(3):425-441.

doi:10.1186/1471-2202-14-S1-P291

Cite this article as: Holt and Netoff: Predicting deep-brain stimulation frequencies to suppress pathological population oscillations in a network model of Parkinson's disease. BMC Neuroscience 2013 14(Suppl 1):P291.

Submit your next manuscript to BioMed Central and take full advantage of:

- Convenient online submission

- Thorough peer review

- No space constraints or color figure charges

- Immediate publication on acceptance

- Inclusion in PubMed, CAS, Scopus and Google Scholar

- Research which is freely available for redistribution

Submit your manuscript at www.biomedcentral.com/submit 